\title{
The Longitudinal Relationships between Depression and Smoking in Hardcore Smokers Using Autoregressive Cross-Lagged Modeling
}

\author{
Han, Jeong Won ${ }^{1 \oplus} \cdot$ Lee, Hanna ${ }^{2 \oplus}$ \\ ${ }^{1}$ College of Nursing Science, Kyung Hee University, Seoul \\ ${ }^{2}$ Department of Nursing, Changwon National University, Changwon, Korea
}

\begin{abstract}
Purpose: This study aimed to identify the directionality of the causal relationship and interaction between depression and amount of smoking over time in hardcore smokers using longitudinal descriptive analysis. Methods: Secondary data from the Korean Welfare Panel Study were analyzed using autoregressive cross-lagged modeling. Participants included 342 hardcore smokers who participated in the 8th to 11th waves of the panel study. Results: Analyses revealed that change(s) in depression levels according to time had a significant positive relationship with the total amount of smoking per day $(\beta=.29, \beta=.19, \beta=.17, \beta<.001)$, while change(s) in total amount of smoking per day according to time had a significant positive relationship with depression $(\beta=.43, \beta=.50, \beta=.38, p<.001)$. Analysis of the cross-lagged effect between depression and total amount of smoking per day showed that depression at one time point had a significantly positive relationship with the total amount of smoking per day at the next time point $(\beta=.14, \beta=.13, \beta=.13, p=.021)$, and that the total amount of smoking per day at one time point had a significant positive relationship with depression at the next time point $(\beta=.04, \beta=.04, \beta=.03, p=.044)$. Conclusion: The findings in the present study confirmed a cross-interaction between depression and total amount of smoking per day in hardcore smokers. The present findings could be used to develop appropriate smoking-related interventions.
\end{abstract}

Key words: Depression; Longitudinal Studies; Smoking

\section{INTRODUCTION}

According to the Report on the Global Tobacco Epidemic by the World Health Organization (WHO), there are approximately 1.1 billion smokers in the world, representing 1 out of 5 adults. Further, among them, approximately 0.5 billion are expected to die from smoking cigarettes [1]. Smoking causes various cancers; has a fatal impact on other cardiac, cerebrovascular, and respiratory diseases; and is known to cause emotional anxiety and depression [2]. Because of the seriousness of the physical and mental health impact of smoking, the current state and cause of smoking are being analyzed multidimensionally to lower the global smoking rate. In addition, various smoking cessation policies have been implemented, including increasing cigarette prices, issuing warning labels on cigarette packs, designating non-smoking zones, conducting smoking cessation education, and imposing advertisement and mass media restrictions. Additionally, smoking cessation programs and promotional campaigns for smoking cessation are being implemented [3]. Though South Korea has also implemented various anti-smoking policies on the national level, the smoking rate among Korean male adults was 45.0\% in 2007 and $39.3 \%$ in 2017, while that among Korean female adults continued to remain steady at 5.3\% in 2007 and $5.5 \%$ at 2017. These statistics suggest that the smoking rate did not decrease signifi-

\footnotetext{
Address reprint requests to : Lee, Hanna

Department of Nursing, Changwon National University, 20 Changwondaehak-ro, Uichang-gu, Changwon 51140, Korea

Tel: +82-55-213-3572 Fax: +82-55-213-3579 E-mail: 2hanno@hanmail. net
}

Received: August 30, 2018 Revised: January 7, 2019 Accepted: January 8, 2019

This is an Open Access article distributed under the terms of the Creative Commons Attribution NoDerivs License. (http://creativecommons. org/licenses/by-nd/4. 0)

If the original work is properly cited and retained without any modification or reproduction, it can be used and re-distributed in any format and medium. 
cantly despite the implementation of various anti-smoking policies [2]. Therefore, it is necessary to focus on hardcore smokers, who have no intention to quit smoking $[4,5]$.

The definition and classification of hardcore smokers varies across countries. However, in South Korea, a hardcore smoker is defined as someone who smokes an average of $\geq 20$ cigarettes per day, is aged $\geq 20$ years, has been smoking for $\geq 5$ years, had not attempted to quit smoking in the past 12 months, and has no intention to do so in the future [6]. Although the percentage of hardcore smokers may vary, they generally account for approximately 5 15\% of all smokers [7-9]. The most important factor in determining whether an individual is a hardcore smoker is nicotine dependence. Higher nicotine dependence makes it more difficult to quit smoking, and it has been reported that the likelihood of becoming a hardcore smoker is higher in those who started smoking at an earlier age, have been smoking for a longer duration, smoke more, and have a lower educational level $[1,10,11]$. Hardcore smokers have a relatively higher nicotine dependence than do regular smokers [12-14]. While current smoking cessation policies may have a positive impact on regular smokers with low nicotine dependence, they have been shown to have a limited impact on hardcore smokers [4]. Accordingly, the development of differentiated smoking cessation policies and interventions targeting hardcore smokers is emphasized [4].

In particular, hardcore smokers become dependent on nicotine, but various behavioral and psychological factors are also interconnected with nicotine dependence $[13,15]$. The theory of smoking proposed by Leventhal and Zvolensky [16] explains that, not only is smoking affected by psychological factors such as anxiety, depression, and stress, but continued smoking also exacerbates these psychological problems. Therefore, a concurrent approach is needed to address an individual's smoking status and psychological problems.

A study on American adolescents reported that students with high levels of depression had a higher risk of smoking because of their lack of skills in coping with rejection [17]. Therefore, depression is considered a risk factor for smoking. Among the studies that identified the relationship between depression and smoking, a study on Australian adults [18] reported that there was a higher probability of hardcore smokers being diagnosed with depression as compared to others, while a study on Korean adults aged $\geq 40$ years reported that former and current smokers showed a significantly higher rate of depression than did non-smokers [19].

On the other hand, smoking has been suggested as a predictor of depression. In a meta-analysis of studies on smoking [20], exposure to secondhand smoking was reported to be associated with depressive symptoms and psychological distress. Nicotine acts on the brain to activate nicotine acetylcholine receptors, triggering the release of large quantities of a variety of neurotransmitters such as dopamine, norepinephrine, and serotonin, which can improve one's mood, and temporarily improving one's memory and ability to perform tasks [21]. Therefore, when a smoker quits smoking, he or she may experience more severe depression or run an increased risk of recurrence due to nicotine withdrawal symptoms, while some of these neurotransmitters have been reported to be involved in the onset and retention of depression [21]. Based on these studies, it has been determined that, while smoking may be increased by negative psychological factors such as depression, excessive smoking can also act as the cause of psychological factors such as depression [16].

Considering that the incidence of smoking has not changed greatly despite continued governmental efforts, policies for hardcore smokers with high nicotine dependence are needed. Further, since psychological factors such as depression have a circular causality with smoking status, an approach based on the same is needed. However, most of the previous smoking-related studies conducted in Korea included both hardcore and regular smokers in the same smoker group [22,23], or studies on hardcore smokers focused only on identifying the prevalence or status of smoking $[8,24]$. In particular, depression and amount of smoking in hardcore smokers are factors that can change in various ways over time, but most previous studies only examined the relationship at a specific time point, which makes it difficult to accurately identify a causal relationship between depression and smoking.

Accordingly, the present study aimed to examine the stability of depression and smoking over time in Korean hardcore smokers, and to identify the directionality of the interaction and causal relationship between these two factors to provide basic data on smoking and mental health in adults. 


\section{Purpose of the study}

The present study aimed to use longitudinal data from the Korea Welfare Panel Study (KOWEPS) to test the causal relationship between depression and smoking in hardcore smokers. The specific purposes were as follows:

To determine whether hardcore smokers exhibit stable levels of depression and amount of smoking according to changes in time.

To determine the directionality of interaction and causal relationship between depression and amount of smoking in hardcore smokers.

\section{METHODS}

\section{Research design}

The present study was a secondary analysis of data extracted from the KOWEPS conducted by the Korea Institute of Health and Social Association (KIHASA). A longitudinal descriptive analysis of causality was conducted to identify the directionality of the interaction and causal relationship between depression and amount of smoking over time in hardcore smokers (Figure 1).

\section{Research participants}

The KOWEPS is a longitudinal study conducted by KIHASA and the Institute of Social Welfare at Seoul National University. It has been conducted in waves every year since 2006, and currently, data are available until 2017. In the first wave of the KOWEPS (2006), 517 tracts were sampled from data representing $90.0 \%$ of the Korean population in the most recent census to investigate household income and economic activity status of household members. From the first phase data, ordinary and low-income households were extracted as sample households, after which stratified double sampling was used to select a total of 7,072 panel households. Following the sixth wave of the KOW$\mathrm{EPS}$, the decrease in the retention of the original sample households was considered, and consequently, the seventh wave of the KOWEPS added approximately 1,800 households as new panels to retain the sample size from the first wave. The sampling method used for this wave was the same as that used in the first wave.

As a general rule, the KOWEPS was conducted as a personal interview survey in which the investigator personally visited the panel households and interviewed the members of the household, recording the responses in Computer Assisted Personal Interviewing (CAPI). To request for cooperation in the survey and to identify households that had moved since the previous wave, a telephone interview was conducted prior to the onsite interview. Moreover, the investigation supervisors visited local government offices (eup, dong, and myeon) to request their cooperation in surveying the panel households within their jurisdiction. Except in certain limited cases where it was difficult for the investigator

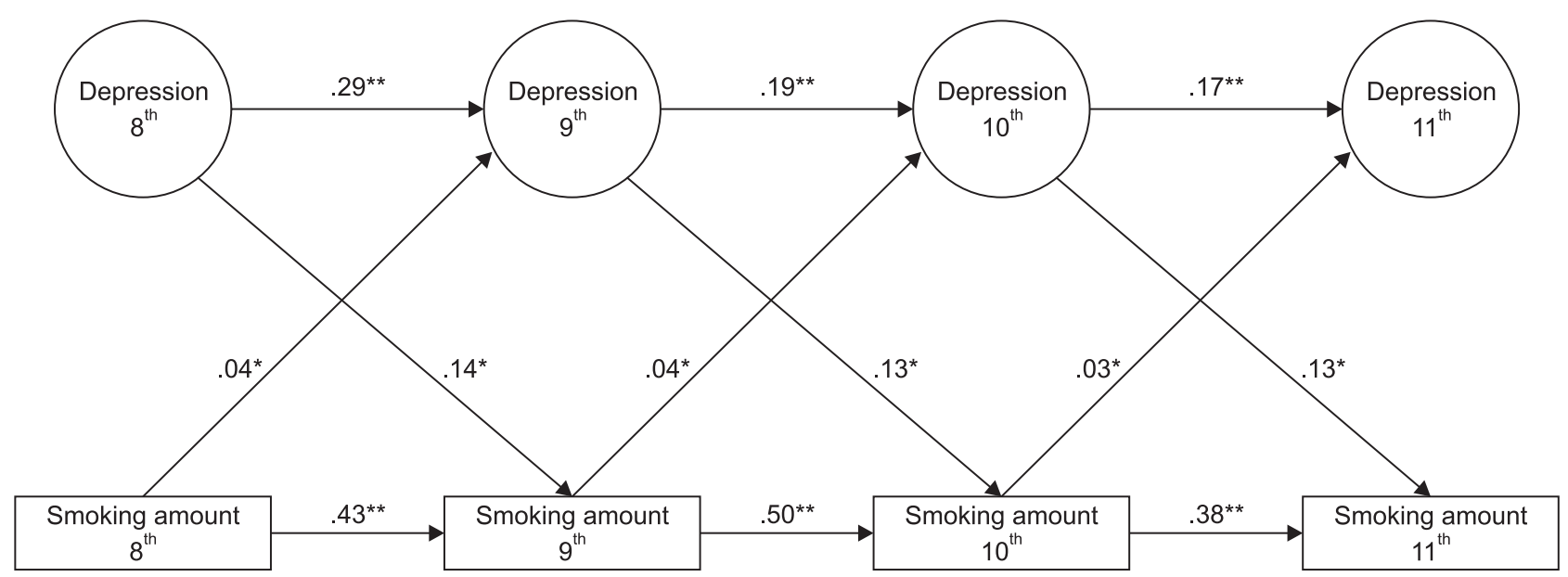

${ }^{* *} p<.001,{ }^{*} p<.05$

Figure 1. Autoregressive cross-lagged modeling. 
to meet with the survey participants in person during the survey period for unavoidable reasons, such as the participant returning home late at night or being away on a long leave, or if the household member was not at home for a certain period of time due to reasons such as living abroad, traveling for vacation or business, hospitalization, and military service, a self-report questionnaire was left with the respondent and the interview was conducted over the phone, or someone else was allowed to respond on behalf of that household member. The investigators were selected from a pool of investigators within KIHASA, with priority given to those with excellent assessment scores from among those with experience in conducting panel and large-scale surveys. The major content of investigator training included an explanation of the survey, using CAPI, greetings to be used when visiting a household, and other precautions related to the survey. The sample retention rate of the KOWEPS, based on the sample of 7,072 households in 2006, was $72.1 \%, 69.2 \%, 67.3 \%$, and $64.5 \%$ in the $8^{\text {th }}$ (2013), $9^{\text {th }}$ (2014), 10 $0^{\text {th }}$ (2015), and $11^{\text {th }}(2016)$ waves, respectively.

The study population of the present study comprised hardcore smokers among all adult smokers aged $\geq 19$ years who participated in the KOWEPS. In the $8^{\text {th }}, 9^{\text {th }}, 10^{\text {th }}$, and $11^{\text {th }}$ waves of the KOWEPS, the number of smokers was 2,758, 2,599, 2,246, and 2,191 , respectively, of which the number of hardcore smokers was 723, 794, 484, and 562, respectively. The present study initially selected 347 hardcore smokers who participated in all surveys from the $8^{\text {th }}$ through $11^{\text {th }}$ waves of the KOWEPS, of whom 5 individuals who responded that they were suffering from or taking medication for depression were excluded. Consequently, 342 people were finally selected as the study participants. The autoregressive cross-lagged model is one of the path analysis models that longitudinally identify the relationships between variables. The appropriate sample size for conducting a path analysis is at least 200 [25], and thus, the 342 participants in this study was deemed as a sufficient sample size.

\section{Measurement}

The measurement tools used in the present study consisted of some of the items measured in the KOWEPS, which were selected according to the purpose of the present study.

\section{1) General characteristics}

The general characteristics of the participants were analyzed by gender, age, highest educational level, type of work, and household income. The participants consisted of members of low-income and moderate households with a median equivalent household income $\geq 60.0 \%$, as assigned to each member of the household by dividing the gender, type of work, and household income by the square root of the number of household members.

\section{2) Total amount of smoking per day}

The total amount of smoking per day represented the numeric value assigned by the respondents to the question "How many cigarettes do you smoke in a day?" at the time of the survey.

\section{3) Depression}

Depression was measured using 11 items in the Center for Epidemiologic Studies Depression (CES-D) scale [24] used in the KOWEPS. Each item was scored on a Likert scale (0: rarely or none of the time, 1: some or a little of the time, 2: occasionally or a moderate amount of the time, and 3: most or all of the time). Among the 11 items, Item 2 and 7 measured positive emotions, and thus the scores for these items were converted accordingly for data analysis. A higher sum of all scores indicated more severe depressive symptoms. The reliability of the tool in the present study was shown by a Cronbach's $\alpha$ of .99, .98, .99, and .99 for the $8^{\text {th }}, 9^{\text {th }}, 10^{\text {th }}$, and $11^{\text {th }}$ waves, respectively.

\section{Ethical considerations}

Data were provided by the KIHASA after deliberation and the study was conducted after receiving waiver for ethical approval (1040271-201807-HR-023) from the Institutional Review Board (IRB) of C University.

\section{Data analysis}

The data used in the present study were obtained by registering and logging in to the homepage of the KOWEPS (https:// www.koweps.re.kr) and inputting the purpose and method of data use. The data provided did not contain any personally identifiable information. The researchers also consulted nursing statistics specialists regarding the statistical methods used in this study. To test the causal relationship between depression and amount of 
smoking in hardcore smokers, the present study combined household and household member data from the $8^{\text {th }}$ through $11^{\text {th }}$ waves of the KOWEPS. For data input and analysis, SPSS WIN 24.0 (SPSS Korea Data Solution Inc) and AMOS 18.0 (SPSS Korea Data Solution Inc) were used, while missing values were handled using the full information maximum likelihood (FIML) assumption method. The general characteristics of the participants were analyzed by frequency, percentage, mean, and standard deviation (SD). Depression and total amount of smoking per day of the participants at each measurement wave point were analyzed by mean and SD, while the correlation between the measured variables was analyzed using the Pearson's correlation coefficient. In addition, the present study used autoregressive cross-lagged modeling to investigate the stability of and causal relationship between depression and total amount of smoking per day over time in hardcore smokers.

To apply autoregressive cross-lagged modeling, four subfactors (depressive affect, positive affect, physical/behavior degradation, and interpersonal difficulties) based on the results of measurement invariance testing of the Korean version of the CES-D short-form [26] were used as the measurement variables of depression. Autoregressive cross-lagged modeling is a method that uses longitudinal data to identify the causal relationship between variables, which offers the advantage of deriving a clear causal relationship between two variables by a multi-faceted testing of their relationship. Autoregressive cross-lagged modeling can be divided into autoregressive modeling and cross-lagged modeling. Autoregressive modeling is the part in which the variable at time point $[t]$ is explained by the same variable at time point $[t-1]$; the value at $[t]$ is explained only by the value at $[t-1]$; and the value at time point $[t+1]$ cannot be explained by the value at time point $[t-1]$ without going through the value at $[t]$. The cross-lagged effect can identify the time-lagged interaction between two variables. The regression equation of autoregressive cross-lagged modeling in the present study was as follows:

Depression $_{\mathrm{i}}[\mathrm{t}]=\beta_{0}[\mathrm{t}]+\beta_{1}$ depression $_{\mathrm{i}}[\mathrm{t}-1]+\beta_{2}$ Depression $_{\mathrm{i}}[\mathrm{t}-1]+\mathrm{r}_{\mathrm{i}}[\mathrm{t}]$ Total amount of smoking per day $\mathrm{j}_{\mathrm{i}}[\mathrm{t}]=\gamma_{0}[\mathrm{t}]+\gamma_{1}$ Total amount of smoking per day $[\mathrm{t}-1]+\gamma_{2}$ Total amount of smoking per day $\mathrm{i}_{\mathrm{i}}[\mathrm{t}-1]+\mathrm{e}_{\mathrm{i}}[\mathrm{t}]$

In the present study, the autoregressive cross-lagged model was tested by a 8-stage model, in the following order: testing the metric invariance to analyze whether the concept measured at each time point was the same, testing the path coefficient invariance to examine whether the regression coefficient of latent variables remained the same over time, and testing the error $\mathrm{co}^{-}$ variance invariance to examine whether error covariance is established. Since each model represents a nested relation, a $t$-test can be applied. However, because it is sensitive to sample size, the normed fit index (NFI), comparative fit index (CFI), Tucker-Lewis index (TLI), and root mean square error of approximation (RMSEA) were also considered to determine the fitness of the models. The specific stages of the models were as follows:

Model 1: Basic model excluding covariance between errors.

Model 2: Model with covariances of $\mathrm{d} 1$ and $\mathrm{d} 2$, $\mathrm{d} 3$ and $\mathrm{d} 4$, and d5 and d6 added to Model 1.

Model 3: Model with equality constraints added to the factor loading of measured variables of depression in Model 2.

Model 4: Model with equality constraints added to the autoregressive coefficient of depression in Model 3.

Model 5: Model with equality constraints added to the autoregressive coefficient of total amount of smoking per day in Model 4.

Model 6: Model with equality constraints added to the crosslagged coefficient of depression relative to the total amount of smoking per day in Model 5.

Model 7: Model with equality constraints added to the crosslagged coefficient of the total amount of smoking per day relative to depression in Model 6.

Model 8: Model with equality constraints added to the variance between the errors of depression and the total amount of smoking per day in Model 7.

\section{RESULTS}

\section{General characteristics of the participants}

The sample comprised 331 males (96.8\%) and 11 females (3.2\%). Their mean age was 51.50 years and the numbers of participants in the age groups of 20 29, 30 39, 40 49, 50 59, 60 69, and $\geq 70$ years were 6 (1.8\%), 53 (15.5\%), 112 (32.7\%), 78 (22.8\%), 54 (15.8\%), and 39 (11.4\%), respectively. The number of participants with an educational level of secondary school 
graduate or below, high school graduate, 2-year college or vocational school graduate, and 4-year university graduate or higher was 113 (33.0\%), 139 (40.6\%), 34 (9.9\%), and 56 (16.4\%), respectively. The number of participants reporting an employment status of wage worker, self-employed or employer, unpaid family worker, and unemployed was 175 (51.2\%), 103 (30.1\%), 2 (0.6\%), and 62 (18.1\%), respectively. Meanwhile, the number of moderate and low-income household members was 261 (76.1\%) and 81 $(23.7 \%)$, respectively.

\section{Correlations and changes in each factor by time}

The variables by years of depression and total amount of smoking per day of the participants showed an absolute skewness value of $<3$ and maintained an absolute kurtosis value of $<10$, thus satisfying the normality assumption (Table 1). The 4-year mean values of depression and total amount of smoking per day showed a tendency of short-term decrease in the $9^{\text {th }}$ wave, increasing again thereafter.

\section{Correlations between measured variables}

Depression and total amount of smoking per day were significantly correlated at all time points (Table 2).

\section{Causal relationships between measured variables}

In the present study, the causal relationships between depression and total amount of smoking per day in hardcore smokers were estimated using autoregressive cross-lagged modeling, which was tested by a 8-stage model in the following order:

Table 1. Descriptive Statistics of Depression and Smoking Amount Over Time

\begin{tabular}{|c|c|c|c|c|c|c|}
\hline Variables & M & SD & Skewness & SE & Kurtosis & SE \\
\hline Depression $8^{\text {th }}$ & 2.08 & 2.38 & 2.51 & 0.13 & 4.53 & 0.26 \\
\hline Depression $9^{\text {th }}$ & 1.60 & 1.41 & 2.56 & 0.13 & 9.07 & 0.26 \\
\hline Depression $10^{\text {th }}$ & 1.96 & 1.40 & 2.34 & 0.13 & 9.43 & 0.26 \\
\hline Depression $11^{\text {th }}$ & 2.09 & 1.54 & 2.85 & 0.13 & 4.84 & 0.26 \\
\hline Smoking amount $8^{\text {th }}$ & 23.35 & 7.04 & 2.37 & 0.13 & 6.26 & 0.26 \\
\hline Smoking amount $9^{\text {th }}$ & 23.12 & 6.59 & 2.11 & 0.13 & 4.07 & 0.26 \\
\hline Smoking amount $10^{\text {th }}$ & 22.43 & 4.27 & 2.53 & 0.13 & 9.05 & 0.26 \\
\hline Smoking amount $11^{\text {th }}$ & 23.52 & 4.35 & 2.09 & 0.13 & 9.89 & 0.26 \\
\hline
\end{tabular}

$\mathrm{M}=$ mean; $\mathrm{SD}=$ standard deviation; $\mathrm{SE}=$ standard error.

Table 2. The Correlation between Depression and Smoking Amount

\begin{tabular}{|c|c|c|c|c|c|c|c|c|}
\hline \multirow{2}{*}{ Variables } & $\mathrm{X} 1$ & $\times 2$ & X3 & $X 4$ & $\times 5$ & $x 6$ & $X 7$ & $x 8$ \\
\hline & $r(p)$ & $r(p)$ & $r(p)$ & $r(p)$ & $r(p)$ & $r(p)$ & $r(p)$ & $r(p)$ \\
\hline Depression $8^{\text {th }}$ & 1 & & & & & & & \\
\hline Depression $9^{\text {th }}$ & $\begin{array}{r}.395 \\
(<.001)\end{array}$ & 1 & & & & & & \\
\hline Depression $10^{\text {th }}$ & $\begin{array}{r}.385 \\
(<.001)\end{array}$ & $\begin{array}{r}.474 \\
(<.001)\end{array}$ & 1 & & & & & \\
\hline Depression $11^{\text {th }}$ & $\begin{array}{c}.311 \\
(<.001)\end{array}$ & $\begin{array}{c}.346 \\
(.003)\end{array}$ & $\begin{array}{r}.367 \\
(<.001)\end{array}$ & 1 & & & & \\
\hline Smoking amount $8^{\text {th }}$ & $\begin{array}{c}.150 \\
(.009)\end{array}$ & $\begin{array}{c}.244 \\
(.007)\end{array}$ & $\begin{array}{c}.164 \\
(.016)\end{array}$ & $\begin{array}{c}.192 \\
(.043)\end{array}$ & 1 & & & \\
\hline Smoking amount $9^{\text {th }}$ & $\begin{array}{c}.185 \\
(.008)\end{array}$ & $\begin{array}{c}.108 \\
(.045)\end{array}$ & $\begin{array}{c}.377 \\
(.007)\end{array}$ & $\begin{array}{c}.110 \\
(.024)\end{array}$ & $\begin{array}{r}.570 \\
(<.001)\end{array}$ & 1 & & \\
\hline Smoking amount $10^{\text {th }}$ & $\begin{array}{c}.062 \\
(.026)\end{array}$ & $\begin{array}{c}.103 \\
(.006)\end{array}$ & $\begin{array}{c}.180 \\
(.007)\end{array}$ & $\begin{array}{c}.202 \\
(.005)\end{array}$ & $\begin{array}{r}.336 \\
(<.001)\end{array}$ & $\begin{array}{r}.430 \\
(<.001)\end{array}$ & 1 & \\
\hline Smoking amount $11^{\text {th }}$ & $\begin{array}{l}.117 \\
(.007)\end{array}$ & $\begin{array}{c}.129 \\
(.003)\end{array}$ & $\begin{array}{l}.170 \\
(.006)\end{array}$ & $\begin{array}{l}.141 \\
(.025)\end{array}$ & $\begin{array}{r}.262 \\
(<.001)\end{array}$ & $\begin{array}{r}.315 \\
(<.001)\end{array}$ & $\begin{array}{r}.375 \\
(<.001)\end{array}$ & 1 \\
\hline
\end{tabular}


Table 3. Multi-Fitness Comparison of ACLM for Depression and Smoking Amount

\begin{tabular}{ccccccc}
\hline Model & $\chi^{2}$ & df & NFI & CFI & TLI & RMSEA \\
\hline Model 1 & 296.74 & 161 & 0.93 & 0.99 & 0.98 & 0.04 \\
Model 2 & 294.15 & 158 & 0.93 & 0.99 & 0.99 & 0.98 \\
Model 3 & 286.60 & 157 & 0.93 & 0.99 & 0.98 & 0.04 \\
Model 4 & 306.94 & 159 & 0.93 & 0.98 & 0.98 & 0.05 \\
Model 5 & 330.24 & 161 & 0.93 & 0.98 & 0.98 & 0.05 \\
Model 6 & 330.74 & 163 & 0.93 & 0.98 & 0.98 & 0.05 \\
Model 7 & 332.02 & 165 & 0.93 & 0.98 & 0.98 & 0.05 \\
\hline Model 8 & 334.32 & 167 & 0.93 & & \\
\hline
\end{tabular}

ACLM=Autoregression Cross-Lagged Model; $d f=$ Degree of freedom; NFI=Normal Fit Index; CFI=Comparative Fit Index; TLI=Turker-Lewis Index; RMSEA=Root Mean Squared Error of Approximation.

Table 4. Parameter Estimation of ACLM between Depression and Smoking Amount

\begin{tabular}{|c|c|c|c|c|}
\hline Pathway & B & $\beta$ & $C R$ & $p$ \\
\hline Depression $8^{\text {th }} \rightarrow$ Depression $9^{\text {th }}$ & 0.18 & 0.29 & 7.45 & $<.001$ \\
\hline Depression $9^{\text {th }} \rightarrow$ Depression $10^{\text {th }}$ & 0.18 & 0.19 & 7.45 & $<.001$ \\
\hline Depression $10^{\text {th }} \rightarrow$ Depression $11^{\text {th }}$ & 0.18 & 0.17 & 7.45 & $<.001$ \\
\hline Smoking amount $8^{\text {th }} \rightarrow$ Smoking amount $9^{\text {th }}$ & 0.37 & 0.43 & 15.99 & $<.001$ \\
\hline Smoking amount $9^{\text {th }} \rightarrow$ Smoking amount $10^{\text {th }}$ & 0.37 & 0.50 & 15.99 & $<.001$ \\
\hline Smoking amount $10^{\text {th }} \rightarrow$ Smoking amount $11^{\text {th }}$ & 0.37 & 0.38 & 15.99 & $<.001$ \\
\hline Depression $8^{\text {th }} \rightarrow$ Smoking amount $9^{\text {th }}$ & 0.12 & 0.14 & 2.31 & .021 \\
\hline Depression $9^{\text {th }} \rightarrow$ Smoking amount $10^{\text {th }}$ & 0.12 & 0.13 & 2.31 & .021 \\
\hline Depression $10^{\text {th }} \rightarrow$ Smoking amount $11^{\text {th }}$ & 0.12 & 0.13 & 2.31 & .021 \\
\hline Smoking amount $8^{\text {th }} \rightarrow$ Depression $9^{\text {th }}$ & 0.06 & 0.04 & 2.01 & .044 \\
\hline Smoking amount $9^{\text {th }} \rightarrow$ Depression $10^{\text {th }}$ & 0.06 & 0.04 & 2.01 & .044 \\
\hline Smoking amount $10^{\text {th }} \rightarrow$ Depression $11^{\text {th }}$ & 0.06 & 0.03 & 2.01 & .044 \\
\hline
\end{tabular}

ACLM=Autoregression Cross-Lagged Model; $C R=$ Construct reliability.

testing the metric invariance to analyze whether the concept measured at each time point was the same, testing the path coefficient invariance to examine whether the regression coefficient of latent variables remained the same over time, and testing the error covariance invariance to examine whether error covariance is established. If there was no decline in the fitness index when equality constraints were applied, invariance was deemed to have been established. Model 8 , where equality constraints were added to the variance between errors, did not show a large difference in the fitness index as compared to Model 7, and thus, Model 8 was selected as the final model (Table 3).

The structure coefficient of the final model (Model 8) has been presented in Figure 1 (Table 4). When the autoregressive effect between depression and total amount of smoking per day was analyzed, depression according to change in time showed a significantly positive relationship $(\beta=.29, \beta=.19, \beta=.17, p<.001)$, while total amount of smoking per day according to change in time also showed a significantly positive relationship $(\beta=.43$, $\beta=.50, \beta=.38, p<.001)$. Analysis of the cross-lagged effects between the study variables revealed that depression at a previous time point had a significantly positive relationship with total amount of smoking per day at the next time point $(\beta=.14, \beta=.13$, $\beta=.13, p=.021$, and that total amount of smoking per day at a previous time point had a significantly positive relationship with depression at the next time point $(\beta=.04, \beta=.04, \beta=.03, p=.044)$. The results showed that the effect of depression on total amount of smoking per day was significantly higher in hardcore smokers than in the effects of total amount of smoking per day on depression.

\section{DISCUSSION}

The present study aimed to examine the stability of depression and total amount of smoking per day over time in Korean hard- 
core smokers and to identify the directionality of the interaction and causal relationship between these two factors to provide basic data for smoking intervention in adults. Based on the findings in the study, the following implications may be discussed.

Majority of the hardcore smokers (96.8\%) were males. Although it is somewhat difficult to make a direct comparison due to varied definitions of hardcore smokers across countries, the present value is overwhelmingly greater than the $85.3 \%$ found in 2005 and $84.4 \%$ in 2008 in the two-round Thematic Household Survey conducted on hardcore smokers in Hong Kong [27]. However, it is similar to or higher than the $92.6 \%, 94.1 \%$, and 95.6\% found in India, Bangladesh and Thailand, respectively, in a study on smoking conducted in South East Asian countries [14]. Further, a study of Korean hardcore smokers [6] showed that the ratio of male hardcore smokers was 2.6 times higher than that of women, and this noticeable difference in hardcore smoking ratios between the sexes in South Korea is attributable to the very low female smoking ratio and socio-cultural factors such as social prejudice against female smoking. Considering the findings that men are more vulnerable to hardcore smoking, it is deemed necessary to conduct appropriate smoking cessation programs for men.

During the period in which the present study was conducted (2013 2016), South Korea increased the prices of tobacco products at a nationwide level, and actively launched anti-smoking policies such as the expansion of smoke-free areas and the enlargement of the size of pictorial warnings on tobacco packages to $30 \sim 50 \%$. Nonetheless, individuals aged 50 years or older accounted for $50.0 \%$ among the hardcore smokers in this study. Kishore et al. [14] also reported that those aged 45 years or older accounted for $52.6 \%$ and $41.5 \%$ of the hardcore smokers in India and Thailand, respectively. This is consistent with Cho's findings [6] that older smokers were more likely to be hardcore smokers. Considering that the more the smoking amount, the more difficult it is for hardcore smokers to stop smoking due to nicotine dependence, it is estimated that the older the smokers, the more accumulative is their smoking amount. As for the educational background of hardcore smokers in this study, 33.0\% had an educational level of middle-school graduate or below, which is similar to the $29.9 \%$ reported by Cho [6] in the study on the hardcore smoking status in South Korea. Thus, it is deemed necessary to conduct smoking cessation education for groups with a low educational level.

The present study also revealed that depression in hardcore smokers at a previous time point had a significant effect on depression at the four subsequent time points. This finding was similar to that reported in a study on American adolescents [17], which found that, even 3 years after smoking initiation, students with high depression maintained their depression level. The present study also found that depression in hardcore smokers was affected even after a certain amount of time had passed. An earlier study on anxiety and depression in smokers [16] reported that depression is a chronic condition in smokers. It is believed that depressive symptoms would inevitably persist because nicotine acts on the brain to affect the nerves through the secretion of neurotransmitters [21]. Therefore, because smoking itself is involved in the onset and persistence of depression, it is necessary for nurses to regularly monitor and address depression in hardcore smokers.

Further, the present study found that hardcore smokers' total amount of smoking per day had a statistically significant effect on the total amount of smoking per day at the four subsequent time points. This finding was consistent with the results reported in other studies, which confirmed that it is difficult for hardcore smokers to quit smoking because of their nicotine addiction symptoms [12-14]. In addition, a study on hardcore smokers in Hong Kong [27] reported that the number of hardcore smokers continued to increase even after the implementation of smokefree legislation, which was attributed to smoking being a habit in hardcore smokers. Such a repetitive life habit thereby leads to a strong nicotine addiction. Therefore, since repetitive and continued smoking due to nicotine addiction is the most important cause of smoking in hardcore smokers, it is necessary to implement more aggressive policies to change their life habits and to provide a social environment conducive to smoking cessation. Moreover, effective customized smoking cessation interventions, different from those for regular smokers, are also needed.

The present analysis of the cross-lagged effect between total amount of smoking per day and depression showed that the total amount of smoking per day at a previous time point had a significantly positive relationship with depression at the next time point, while depression at a previous time point had a significantly 
positive relationship with total amount of smoking per day at the next time point. These findings are similar to those of a study that reported that it is difficult for smokers with mental illness to quit smoking [28]. Moreover, the findings also support an earlier study that reported that smoking makes it difficult to treat depression and that it is the strongest predictor of suicidal behavior [29]. In a systematic review of the literature on the association between smoking and depression/anxiety [30], about half of the 148 studies reviewed reported that depression/anxiety is associated with smoking behavior, while more than one-third reported that smoking is associated with depression/anxiety at a later time. However, there were almost no studies that supported a bidirectional relationship between the factors, while most of the studies to date focused on the unidirectional effect of psychological/emotional factors, such as the effect of depression on smoking or that of smoking on depression. Accordingly, it was suggested to use different methodologies to examine this relationship [30].

The findings in the present study confirmed a cross interaction between depression and total amount of smoking per day in hardcore smokers, and it is believed that the causal relationship between smoking and depression constitutes a vicious cycle without easily distinguished dependent and independent variables. In South Korea, for the smoking cessation of hardcore smokers, governmental agencies, including the Ministry of Health and Welfare, are conducting smoking cessation camps, and hospitals and clinics are introducing smoking cessation counseling programs. However, these programs only perform health status assessments, including health examinations, smoking history, nicotine dependence assessment, and carbon monoxide measurement. They do not assess or intervene for psycho-emotional factors such as depression. A preceding study [27] reported that psycho-emotional problems make smoking cessation more difficult. Therefore, smoking cessation interventions and policies for hardcore smokers should be differentiated to include the regular assessment of psychological/emotional factors, including depression, as well as treatments for nicotine addiction.

The present study analyzed the cross-lagged effect to determine the preceding causality between the two factors. The results showed that the size of the regression coefficient for the effect of depression on total amount of smoking per day was relatively larger than that of the effect of total amount of smoking per day on depression. These findings confirmed that the effect of depression on total amount of smoking per day was greater than that of total amount of smoking per day on depression. This is consistent with the previous finding [16] that smoking is affected by psychological factors such as depression. Here, it is important to consider that depression increases vulnerability to smoking [17]. Further, nicotine works on the brain to secrete a large amount of neurotransmitters such as dopamine, norepinephrine, and serotonin, which lift up mood and temporarily improve memory and task performance, thereby making the smoking cessation all the more difficult [21]. Accordingly, it is important for nurses who care for hardcore smokers to assess their depression and total amount of smoking per day. Further, it is recommended that the obligatory inclusion of depression intervention in smoking cessation programs will be effective in achieving successful smoking cessation.

This study is significant for nursing practice because it considered factors that have a mutual influence on smoking cessation. This longitudinal analysis of the KOWEPS provides basic data for the development of effective interventions and policies on smoking cessation. In addition, these findings are expected to contribute to the knowledge and practice of nurses working with hardcore smokers.

However, this study has some limitations. First, it measured the variables using a limited number of items due to the nature of the large-scale panel data. Therefore, future studies should expand the model by including other variables that are expected to have theoretical relationships with depression and hardcore smoking. Next, the sampling error was large, especially when calculating the ratio of female hardcore smokers, because a small proportion of the present participants were female, and because the sample included various age groups. Thus, it will be necessary for future studies to identify the relationships between smoking and depression by focusing on female smokers or hardcore smokers of the same age groups.

\section{CONCLUSION}

Previous studies of smoking examined the relationships of relevant variables from a cross-sectional perspective. In contrast, the present study used autoregressive cross-lagged modeling to 
identify the interactions between smoking and depression, and their changes over time. In doing so, the study aimed to establish a basis for applying smoking-related intervention at the appropriate time. In addition, earlier studies of adult smokers did not classify the participants based on their smoking status, whereas the present study was different in that it focused on hardcore smokers with high nicotine dependence within the smoker population. Previous studies have also reported that current smoking cessation policies have a positive effect on regular smokers but a limited effect on hardcore smokers. Accordingly, the present findings can be used to develop differentiated smoking cessation policies and intervention programs targeting hardcore smokers in Korea.

\section{CONFLICTS OF INTEREST}

The authors declared no conflict of interest.

\section{REFERENCES}

1. World Health Organization (WHO). Prevalence of tobacco smoking [Internet]. Geneva: WHO; c2015 [cited 2018 Aug 21]. Available from http://www.who.int/gho/tobacco/use/en.

2. Korea Centers for Disease Control and Prevention (KCDC). Korea health statistics 2016: Korea national health and nutrition examination survey (KNHANES VII-1) [Internet]. Cheongju: KCDC; c2017 [cited 2018 Aug 21]. Available from: http://www.cdc.go.kr/CDC/contents/CdcKrContentView. jsp cid $=60949 \&$ menuIds $=$ HOME001-MNU1130-MNU1639MNU1749-MNU1761.

3. World Health Organization (WHO). WHO report on the global tobacco epidemic, 2017: Monitoring tobacco use and prevention policies [Internet]. Geneva: WHO; c2017 [cited 2018 Aug 21] . Available from: http://apps.who.int/iris/bitstream/10665/2 55874/1/9789241512824-eng.pdf?ua = $1 \& u a=1$.

4. Bommelé J, Schoenmakers TM, Kleinjan M, van Straaten B, Wits E, Snelleman M, et al. Perceived pros and cons of smoking and quitting in hard-core smokers: A focus group study. BMC Public Health. 2014;14:175. https://doi.org/10.1186/1471-2458-14-175

5. Lund M, Lund KE, Kvaavik E. Hardcore smokers in Norway 1996-2009. Nicotine \& Tobacco Research. 2011;13(11):11321139. https://doi.org/10.1093/ntr/ntr166

6. Cho KS. Prevalence of hardcore smoking and its associated factors in Korea. Health and Social Welfare Review.
2013;33(1):603-628.

https://doi.org/10.15709/hswr.2013.33.1.603

7. Augustson E, Marcus S. Use of the current population survey to characterize subpopulations of continued smokers: A national perspective on the "hardcore" smoker phenomenon. Nicotine \& Tobacco Research. 2004;6(4):621-629. https://doi.org/10.1080/14622200410001727876

8. Jarvis MJ, Wardle J, Waller J, Owen L. Prevalence of hardcore smoking in England, and associated attitudes and beliefs: Cross sectional study. BMJ. 2003;326:1061. https://doi.org/10.1136/bmj.326.7398.1061

9. Walsh RA, Paul CL, Tzelepis F, Stojanovski E. Quit smoking behaviours and intentions and hard-core smoking in New South Wales. Health Promotion Journal of Australia. 2006;17(1):5460. https://doi.org/10.1071/he06054

10. Ferketich AK, Gallus S, Colombo P, Pacifici R, Zuccaro P, La Vecchia C. Hardcore smoking among Italian men and women. European Journal of Cancer Prevention. 2009;18(2):100-105. https://doi.org/10.1097/CEJ.0b013e32830c8d98

11. Marques-Vidal P, Melich-Cerveira J, Paccaud F, Waeber G, Vollenweider P, Cornuz J. Prevalence and factors associated with difficulty and intention to quit smoking in Switzerland. BMC Public Health. 2011;11:227. https://doi.org/10.1186/1471-2458-11-227

12. Bommelé J, Kleinjan M, Schoenmakers TM, Burk WJ, van den Eijnden R, van de Mheen D. Identifying subgroups among hardcore smokers: A latent profile approach. PLoS One. 2015;10(7):e0133570. https://doi.org/10.1371/journal.pone.0133570

13. Joly B, D'Athis P, Gerbaud L, Hazart J, Perriot J, Quantin C. Smoking cessation attempts: Is it useful to treat hard core smokers? Tobacco Induced Diseases. 2016;14:34. https://doi.org/10.1186/s12971-016-0100-0

14. Kishore J, Jena PK, Bandyopadhyay C, Swain M, Das S, Banerjee I. Hardcore smoking in three South-East Asian countries: Results from the global adult tobacco survey. Asian Pacific Journal of Cancer Prevention. 2013;14(2):625-630. https://doi.org/10.7314/APJCP.2013.14.2.625

15. Heishman SJ. Behavioral and cognitive effects of smoking: Relationship to nicotine addiction. Nicotine \& Tobacco Research. 1999;1(Suppl 2):S143-S147. https://doi.org/10.1080/14622299050011971

16. Leventhal AM, Zvolensky MJ. Anxiety, depression, and cigarette smoking: A transdiagnostic vulnerability framework to understanding emotion-smoking comorbidity. Psychological Bulletin. 2015;141(1):176-212. https://doi.org/10.1037/bul0000003

17. Weiss JW, Mouttapa M, Cen S, Johnson CA, Unger J. Longitudinal effects of hostility, depression, and bullying on adolescent smoking initiation. Journal of Adolescent Health. 
$2011 ; 48(6): 591-596$. https://doi.org/10.1016/j.jadohealth.2010.09.012

18. Bonevski B, Regan T, Paul C, Baker AL, Bisquera A. Associations between alcohol, smoking, socioeconomic status and comorbidities: Evidence from the 45 and up study. Drug and Alcohol Review. 2014;33(2):169-176. https://doi.org/10.1111/dar.12104

19. Chu JE, Lee H, Yoon CH, Cho HI, Hwang JY, Park YJ. Relationships between depressed mood and life style patterns in Koreans aged 40 years. Journal of the Korean Society of Food Science and Nutrition. 2014;43(5):772-783. https://doi.org/10.3746/jkfn.2014.43.5.772

20. Zeng YN, Li YM. Secondhand smoke exposure and mental health in adults: A meta-analysis of cross-sectional studies. Social Psychiatry and Psychiatric Epidemiology. 2016;51(9):1339-1348. https://doi.org/10.1007/s00127-015-1164-5

21. Hammer GD, McPhee SJ. Pathophysiology of disease: An introduction to clinical medicine. 7th ed. New York: McGraw-Hill Education; 2014. p. 145-250.

22. Ko BJ, Chun EJ, Bae Y, Lee JH, Park KA, Jang M, et al. Depressive symptoms in a rural community: Prevalence and related risk factors. Korean Journal of Health Promotion and Disease Prevention. 2008;8(4):228-234.

23. Yoon SH, Bae JY, Lee SW, An KE, Kim SE. The effects of job depression, drinking, and smoking among Korean man. Health and Social Science. 2006;19:25-42.
24. MacIntosh H, Coleman T. Characteristics and prevalence of hardcore smokers attending UK general practitioners. BMC Family Practice. 2006;7:24. https://doi.org/10.1186/1471-2296-7-24

25. Selig JP, Little TD. Autoregressive and cross-lagged panel analysis for longitudinal data. In: Laursen BP, Little TD, Card NA, editors. Handbook of Developmental Research Methods. New York: Guilford Press; 2011. p. 265-278.

26. Hoe MS, Park BS, Bae SW. Testing measurement invariance of the 11-item Korean version CES-D scale. Mental Health \& Social Work. 2015;43(2):313-339.

27. Leung DYP, Chan SSC, Chan V, Lam TH. Hardcore smoking after comprehensive smoke-free legislation and health warnings on cigarette packets in Hong Kong. Public Health. 2016;132:50-56. https://doi.org/10.1016/j.puhe.2015.10.007

28. Smith PH, Homish GG, Giovino GA, Kozlowski LT. Cigarette smoking and mental illness: A study of nicotine withdrawal. American Journal of Public Health. 2014;104(2) :e127-e133. https://doi.org/10.2105/AJPH.2013.301502

29. Prochaska JJ. Smoking and mental illness: Breaking the link. The New England Journal of Medicine. 2011;365(3):196-198. https://doi.org/10.1056/NEJMp1105248

30. Fluharty M, Taylor AE, Grabski M, Munafò MR. The association of cigarette smoking with depression and anxiety: A systematic review. Nicotine \& Tobacco Research. 2017;19(1):313. https://doi.org/10.1093/ntr/ntw140 